\title{
Shoot Regeneration from Leaf Explants of Withania somnifera (L.) Dunal
}

\author{
Aruna Girish JOSHI, Mainavati A. PADHYA \\ The Maharaja Sayajirao University of Baroda, Faculty of Science, Department of Botany, Vadodara-390 002, India; arunajoshi@gmail.com
}

\begin{abstract}
Regeneration from leaf explants of Withania somnifera (L.) for mass propagation was studied on Murashige and Skoog's medium supplemented with Kinetin $(\mathrm{Kn})$ and 6-benzylaminopurine (BAP) alone or in combination. Shoot buds were induced from the midrib on the abaxial side in presence of Kn and BAP $(4 \mu \mathrm{M})$. These shoot buds developed into shoots on the same medium. Rooting of these shoots was achieved in $0.5 \mu \mathrm{M}$ of IBA.
\end{abstract}

Keywords: cytokinin, regeneration, shoot buds

\section{Introduction}

Withania somnifera (L.) Dunal belonging to family Solanaceae is well known for its medicinal properties and frequently used in traditional system of medicine. It is used in relief of pain, cure of skin disease, diabetes, gastrointestinal disorders, rheumatism, epilepsy and for improvement in general health (Tripathi et al., 1996). This species propagates easily by seeds but does not have the natural ability for regenerative propagation, and hence the variability generated by sexual recombination is difficult to fix (Jayanti and Sharma, 1991). In vitro propagation of this useful medicinal plant could provide a means of disease free healthy clones for extraction of pure drugs. This communication reports the morphogenetic capacity of the excised leaves of $W$. somnifera (L.) Dunal.

\section{Materials and methods}

Healthy leaves were collected from elite plants of Withania somnifera (L.) Dunal from the M. S. University Botanical Garden. First to fourth leaf from the apex of branch in a serial order of development was used as explants. Leaves were washed under running tap water for 1 hour and then with teepol. They were surface sterilized with $0.1 \% \mathrm{HgCl}_{2}$ $(\mathrm{w} / \mathrm{v})$ and washed three times with sterile distilled water. The entire leaves were cultured on Murashige and Skoog's (MS) medium (1962) containing sucrose (3\%) and supplemented with different concentrations of Kn/BAP (2-6 $\mu \mathrm{M})$. They were cultured with their abaxial surface in direct contact with the nutrient medium.

For rooting $4-5 \mathrm{cms}$ shoots were transferred to half strength MS medium containing sucrose (1\%) supplemented with various concentrations of IBA $(0.5-2 \mu \mathrm{M})$.
The $\mathrm{pH}$ of all the media was adjusted to 5.8 and autoclaved at $1.1 \mathrm{~kg} / \mathrm{cm}^{2}\left(121^{\circ} \mathrm{C}\right)$ for 20 minutes. All the cultures were incubated under white fluorescent light (2000 lux) for $16 / 8 \mathrm{hr}$ light/dark at $25 \pm 2^{\circ} \mathrm{C}$. In all the experiments 15 replicates were maintained and the experiment was repeated twice.

\section{Results and discussion}

First to third leaves when cultured on all test media failed to regenerate any organs and turned white within four weeks. The fourth leaf when cultured on MS basal medium without growth regulators was unable to show any morphogenetic response. In presence of an individual cytokinin Kn / BAP $(2-6 \mu \mathrm{M})$ the leaf swelled and remained green for four weeks but failed to differentiate any shoot buds.

The foliar explants responded when Kn along with BAP was added in the medium. In presence of both $\mathrm{Kn}$ and BAP $(2-6 \mu \mathrm{M})$ the leaves swelled in size and shoot bud induction took place from the midrib present on the lower surface. Lower concentrations of $\mathrm{Kn}(2 \mu \mathrm{M})$ and BAP (2 $\mu \mathrm{M})$ could evoke a poor morphogeneic response with the induction of meager number of buds (2.16 \pm 0.4$)$. Keeping $\mathrm{Kn}$ constant and increasing the BAP level to $4 \mu \mathrm{M}$ led to increase in the number of shoot buds. Induction of shoot buds was observed as swelling of the midrib on the lower surface of the lamina followed by formation of greenish protuberances (Fig. 1) from it at the end of two weeks of culture. A maximum number of $12.1 \pm 1.2$ shoot buds were formed in $90 \%$ cultures when both the cytokinins were at $4 \mu \mathrm{M} / \mathrm{l}$ (Tab. 1). This combination proved to be optimal for induction of shoot buds as further increase in BAP level to $6 \mu \mathrm{M} / \mathrm{l}$ with the same concentration of $\mathrm{Kn}$ decreased 
64

Tab. 1. Effect of cytokinin on leaf explants of $W$. somnifera (Mean \pm SE)

\begin{tabular}{cccc}
\hline Cytokinin $(\mu \mathrm{M})$ & $\begin{array}{c}\text { Average no. of shoot } \\
\text { buds/ explant }\end{array}$ & $(\%)$ Response \\
\hline \multicolumn{2}{c}{ MS basal medium } & - & - \\
Kn & - & - \\
\multicolumn{2}{c}{$2-6$} & - & - \\
\multicolumn{2}{c}{ BAP 2-6 } & Kn + BAP & - \\
\hline & & $2.16 \pm 0.4$ & 50 \\
\hline 2 & 2 & $5.1 \pm 0.62$ & 55 \\
\hline 2 & 4 & $6.1 \pm 0.62$ & 62 \\
\hline 4 & 2 & $7.6 \pm 1.2$ & 85 \\
\hline 4 & 4 & $12.1 \pm 1.52$ & 90 \\
4 & 6 & $4.0 \pm 1.0$ & 70 \\
\hline 6 & 2 & - & - \\
6 & 4 & - & - \\
\hline 6 & 6 & - & \\
\hline
\end{tabular}

the number of buds. Similar findings are reported in stem discs of Curculigo orchioides, where MS medium fortified with $\mathrm{BAP}$ and $\mathrm{Kn}$ at $1 \mathrm{mg} / \mathrm{l}$ each had a synergistic effect on shoot buds induction from its abaxial surface (Nagesh et al., 2009). Induction of adventitious shoot bud regeneration from leaf discs of neem in presence Kn and BAP has been reported by Ramesh and Padhya (1990). When $\mathrm{Kn}$ at $6 \mu \mathrm{M}$ was combined with different concentrations of BAP failed to induce shoot buds from the explant.

Tab. 2. Effect of IBA on in vitro rooting in $W$. somnifera (Mean \pm SE)

\begin{tabular}{cccc}
\hline $\begin{array}{c}1 / 2 \mathrm{MS}+ \\
\text { IBA }(\mu \mathrm{M})\end{array}$ & $\begin{array}{c}(\%) \\
\text { Rooting }\end{array}$ & $\begin{array}{c}\text { Root number/ } \\
\text { shoot }\end{array}$ & $\begin{array}{c}\text { Root } \\
\text { morphology }\end{array}$ \\
\hline 0.5 & 80 & $1.66 \pm 0.188$ & $\mathrm{~A}$ \\
1.0 & 60 & $1.16 \pm 0.09$ & $\mathrm{~A}$ \\
1.5 & 40 & $2.44 \pm 0.417$ & $\mathrm{~B}$ \\
2.0 & 20 & $2.83 \pm 0.467$ & $\mathrm{C}$ \\
\hline
\end{tabular}

$\mathrm{A}=$ long and stout $\mathrm{B}=$ thick and short $\mathrm{C}=$ very thick

In order to find out the ability for plantlet formation, the shoot buds were detached from the explant and cultured on fresh medium of the same composition. Within two weeks of subculture the shoot buds started to grow into healthy shoots (Fig. 2) and new buds were produced from the base of this cluster by the end of four weeks. Govindraju et al., (2003) have reported direct regeneration from leaf explants for the same plant, but adventitious buds were formed when MS medium was supplemented with BAP (1.0-3.0 mg/l) along with IAA $(0.5 \mathrm{mg} / \mathrm{l})$ and Coconut milk (10\%). Findings of Sivanesan and Murugesan (2005) have shown that the frequency of shoot bud regeneration varied with the level of plant growth regulators in the medium and the highest frequency of shoot

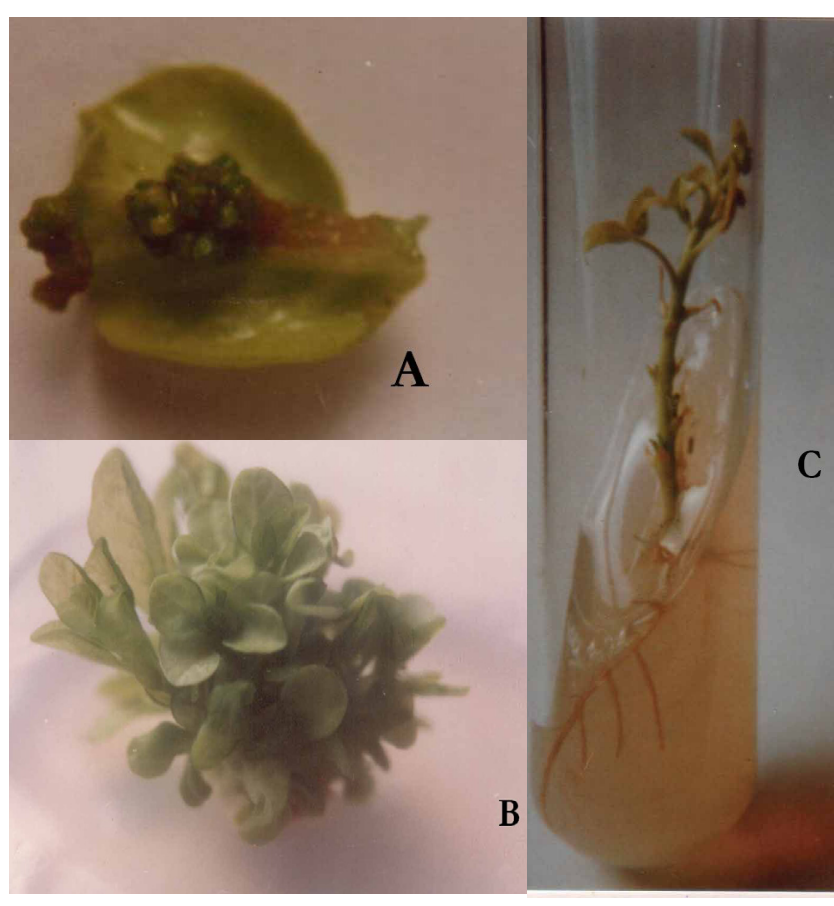

Fig. 1. A) Induction of adventitious buds from abaxial surface of leaf in presence of $\mathrm{Kn}(4 \mu \mathrm{M})+\mathrm{BAP}(4 \mu \mathrm{M})$; B) Further growth of the shoot buds after subculture to fresh medium ;C) Rooting of $W$. somnifera microshoot on half strength MS medium $+\operatorname{sucrose}(1 \%)+$ IBA $(0.5 \mu \mathrm{M})$

buds from leaf explant was obtained in presence of only $1.0 \mathrm{mg} / \mathrm{l}$ of Kinetin.

In our studies the observations revealed that the explant in presence of individual cytokinin does not regenerate shoot buds. When two cytokinins are incorporated in the medium their synergistic effect induces shoot bud regeneration. Both the cytokinins were essential for this response. Similar results have been observed in leaf explants of $\mathrm{Cra}$ taeva nurvula (Sharma and Padhya, 1989). Vincent et al. (1992) have also reported in Kaempferia galanga that MS medium supplemented with Kn and BAP together proved synergistic for induction of shoot buds from leaf explants. Sundhersan (1998) have reported adventitious shoot buds from excised leaf explants of Enicostemma axillare when cultured on MS medium supplemented with BAP.

In vitro rooting was successfully achieved from microshoots of $W$. somnifera with various concentration of IBA $(0.5 \mu \mathrm{M}-2 \mu \mathrm{M})$ as shown in Tab. 2.

Initiation of roots was observed after week of transfer of shoots to half strength MS medium containing sucrose (1\%) and supplemented with different concentrations of IBA. Long stout roots initiated from the base of the shoots in $80 \%$ cultures in presence of $0.5 \mu \mathrm{M}$ IBA (Fig. 1C). In a similar way, IBA $(0.5 \mu \mathrm{M})$ induced optimum rooting in individual elongated shoots of Tylophora indica obtained from leaf derived callus (Faisal and Anis, 2003). With increase in IBA to $1 \mu \mathrm{M}$ showed same response as above but 
there was a decrease in \% response of cultures. For further concentrations the number of roots induced were slightly more but they became thick and short. Sivanesan and $\mathrm{Mu}-$ rugesan (2008) for the same plant reported that IBA was efficient in inducing roots (100\%) in regenerated shoots obtained from nodal explants.

The rooted plants were hardened in sand:soil $(3: 1)$ mixture, and then transferred to greenhouse conditions.

\section{Conclusions}

This study provides a protocol for the adventitious shoot bud regeneration from leaf explants of $W$. somnifera for mass propagation. Leaf explants showed higher morphogenetic potential in presence of $\mathrm{Kn}$ and BAP each at $4 \mu \mathrm{M} / \mathrm{l}$.

\section{References}

Faisal, M. and M Anis (2003). Rapid mass propagation of Tylophora indica (Burm. f.) Merrill via leaf callus culture. Plant Cell, Tissue and Organ Culture. 75:125-129.

Govindraju, B., R. Ramgopal, R. B. Venugopal, S. G. Kiran, C. P. Kaviraj and R. Srinath (2003). High frequency Plant Regeneration in Ashwagandha (Withania somnifera (L.) Dunal): An Important medicinal plant. Plant Cell Biotechnology and Molecular Biology. 4 (1-2):49-56.

Jayanti, S. and A. K. Sharma (1991). Micropropagation of Withania somnifera from germinating seeds and shoot tips. Plant Cell, Tissue and Organ Culture. 26:71-73.

Kallahally, S. N., C. Shanthamma and N. Bhagyalakshmi (2009). Role of polarity in de novo shoot bud initiation from stem disc explants of Curculigo orchioides Gaertn. and its encapsulation and storability. Acta Physiologiae Plantarum. 31:699-704
Murashige, J. and F. Skoog (1962). A revised medium for rapid growth and bioassay with tobacco tissue culture. Physiology Plantarum. 15:473-497.

Ramesh, K. and M. A. Padhya (1990). In vitro propagation of neem, Azadirachta indica (A. Juss), from leaf disks. Indian Journal of Experimental Biology. 28:932-935.

Sharma, V. and M. A. Padhya (1989). In Vitro plantlet regeneration from excised leaves of Crataeva nurvala, pp. 12-16. In: Tissue Culture and Biotechnology of Medicinal and Aromatic Plants.

Sivanesan, I. and K. Murugesan (2005). In vitro adventitious shoot formation from leaf explants of Withania somnifera Dunal. Plant Cell Biotechnol. Mol. Biol. 6:163-166.

Sivanesan, I. and Murugesan (2008). An efficient regeneration from nodal explants of Withania somnifera Dunal Asian journal of Plant Sciences. 7(6):551-556.

Sudhersan, C. (1998). Shoot bud regeneration from leaf explants of a medicinal plant Enicostemma axillare. Current Science. 74:1099-1100.

Tripathi, K.A., Y.N. Shukla and K. Sushil (1996). Ashwagandha (Withania somnifera Dunal Solanaceae): A Status Report Journal of Medicinal and Aromatic Plant Sciences. 18:4662.

Vincent, K. A., K. M. Mathew and M. Hariharan (1992). Micropropogation of Kaempferia galanga L. a medicinal plant. Plant Cell, Tissue and Organ Culture. 28:229-230. 